\title{
Healthcare workers baulk at caring for contagious patients
}

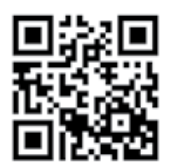

Globally, healthcare workers (HCWs) are reluctant to care for highly infectious patients, with over half surveyed in the USA saying it was acceptable not to pitch up for work during an outbreak of (for example) avian flu, World Health Organization (WHO) surveys show.

Dr Andreas Reis, strategy ambassador for strengthening and developing the WHO's regional institutional capacity and carrying out its mandated projects, said there were widely differing country attitudes to the vexed question of HCWs exposing themselves to high-risk infection. He was speaking after a ceremony on the Tygerberg campus of Stellenbosch University designating its Centre for Medical Ethics and Law as a WHO Collaborating Centre. Reis said that in Taiwan, China, about $57 \%$ of nurses indicated that they were willing to care for patients infected with avian flu, the perception of the importance of their role being the most influential factor. However, in Germany this figure rose to $72 \%$, while just $28 \%$ agreed that it would be professionally acceptable to abandon their workplace in order to protect themselves and their families. Most German HCWs (58\%) did not believe that the decision to report to work during a pandemic should be left to the individual HCW, yet $77 \%$ of them disagreed that HCWs should be dismissed for not reporting to work. In Canada, doctors who wanted to abandon posts during the 2003 outbreak of severe acute respiratory syndrome (SARS) in Toronto faced threats of ostracism.

Reis said that the American Nurses' Association's advice to HCWs was 'to engage in critical thinking and ethical analysis'. Arguments for a moral obligation included an HCW's ability to provide care being greater than that of the public, that they freely chose their profession knowing it had inherent risks, and that there was an unspoken social contract. However, limits and conflicts included the dual role of caring for oneself and one's family and the balance of immediate benefits to individual patients with the ability to care for patients in the future. Governments and employers had a reciprocal obligation to minimise the risk to HCWs. These included ensuring adequate infection control systems, providing preventive measures (e.g. pharmaceuticals, personal protective equipment), and taking a stand on the thorny issue of whether HCWs should have preferential access to experimental drugs, or receive priority treatment, prophylaxis or vaccines. Yet another obligation included putting in place death and disability benefits for HCWs.

\section{Human resources key to any humanitarian response}

Reis said that sufficient human resources formed the foundation of any effective response to a humanitarian crisis. The 2013 WHO report 'A Universal Truth: No health without a workforce' showed that there was a global shortage of almost 7.2 million doctors, midwives and nurses, plus healthcare support staff. This figure is likely to grow to nearly 12 million in the next 18 years. He said that the concept of ethical duties was formally introduced in the USA in 1847 in 'fairly absolute terms', with the American Medical Association declaring 'when pestilence prevails it is the physician's duty to face the danger, even at the jeopardy of his or her own life. By the 1980s, with the advent of HIV/AIDS, vigorous debate about the duty to care gave rise to more sophisticated and subtle approaches. These resulted in moral, professional, contractual,

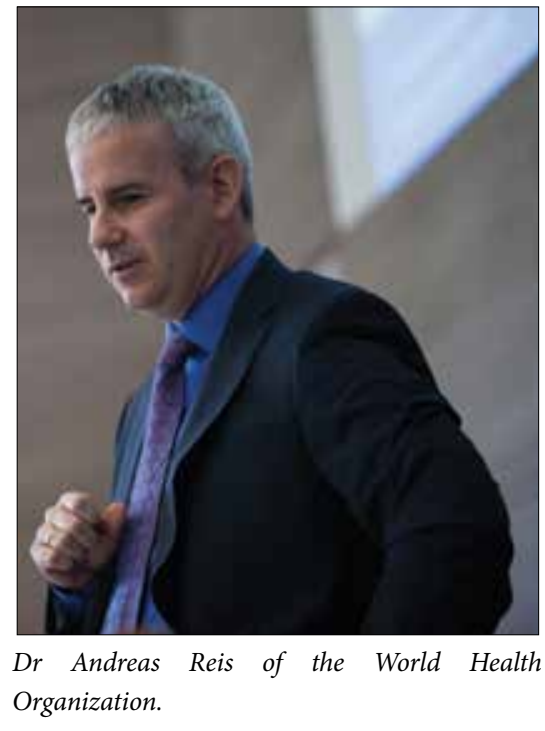

voluntary and legal obligations, none of them mutually exclusive or interdependent.

Prof. Anton van Niekerk, Director of Stellenbosch University's Centre for Applied Ethics and Chairperson of its Department of Philosophy, said that the real question was the level and intensity of risk that HCWs were prepared to face. He defined a 'risk decision' as being based on a balance between beneficial and adverse outcomes, adding that it was 'an irony of the modern world that just when we thought we had serious disease more or less under control, AIDS pops out, followed by SARS and now Ebola; who knows what's around the next corner? For example, what are the possible implications of climate change in terms of disease and the availability of nourishment? HCWs had been running personal risks since the time of the Good Samaritan - the prototype of the 'good doctor', who even paid the innkeeper to care for the injured man. However, 
professionalism (also among police, soldiers, fire-fighters and lifesavers) implied specialised skills that certain emergency situations called for. A high premium was placed on $\mathrm{HCWs}^{2}$ duty to their patients, particularly when those patients were completely dependent on medical professionals (he cited surgeons and anaesthetists). He drew a distinction between actual and prima facie duties, the former being what one 'should' do (a moral decision/action) and the latter a conditional duty that one fulfilled, unless it conflicted with an equal or stronger obligation. Van Niekerk argued that there was no 'absolute duty of care'. However, a catastrophic humanitarian crisis was a typical example of a prima facie duty that could only be determined once all the relevant factors had been considered.

\section{In Taiwan, China, about 57\% of nurses indicated that they were willing to care for patients infected with avian flu, the perception of the importance of their role being the most influential factor. However, in Germany this figure rose to $72 \%$.}

\section{South Africa void of 'duty to care' directives} Van Niekerk said he could find little or nothing' in terms of South African directives about the duty to care in high-risk situations. The Constitution, while stating that nobody may be refused emergency medical treatment (Article 27, which the South African Medical Association endorsed), dealt mainly with basic rights such as health, food, water and social security. The Health Professions
Council of South Africa guidelines for good practice urged HCWs to act quickly to protect patients from risk' if they believed they were impaired, while providing healthcare within the scope of the HCW's practice, experience and competencies in emergency situations. If unable to do this, they were advised to refer the patient to a colleague or facility where the required care could be provided. Van Niekerk wryly commented that 'this becomes a bit moot in West Africa's Ebola areas'.

Health catastrophes that imposed the risk of infection, serious illness and the possible death of HCWs could 'clearly' not be regarded as requiring an absolute obligation on their part. Services in such situations 'can and must only be voluntary?. Factors that played a role in deciding the need and efficacy of care in such situations included where the HCWs worked, what their specialty was, whether patients would actually benefit, and whether it was worth while risking HCW lives for people who would die in any case. 'My argument is that the over-riding moral concern is consent and never coercion, he added. Van Niekerk stressed that the time to decide one's level of commitment in the face of threats to personal safety was not during a public health emergency, but beforehand. Backing Reis's earlier input, he said that policies became paramount in supporting HCWs to reach a decision themselves. This involved careful evaluation of suitable candidates (did they have dependents, their general psychological disposition, levels of adherence to rules and regulations, i.e. no 'cowboys'), optimal knowledge of the crisis and 'risk-required' behaviour, optimal resources, remunerative support (i.e. danger pay), and realistic expectations from patients.

\section{The tragic vaccination lesson of Haiti}

Prof. Dave Durrheim, Director of Public Health Medicine at the University of Newcastle in New South Wales, Australia, said that the first time ethical issues were made as important as any others was after the 'colossal wake-up call' of the January 2010 Haiti earthquake, which was immediately followed by a highly destructive hurricane. The double blow cost 220000 lives with 300000 injuries. He said that humanitarian workers brought cholera with them and the national government dithered on making a decision about oral vaccination, miring itself in political rationalisation. By the end of last year 700000 cholera cases had been confirmed, with 10000 deaths. 'How many lives could have been saved we'll never know, but it illustrates the point that a much more generic response is required, he said.

Asked about the WHO's tardy response to Ebola in West Africa (i.e. only when international containment became an issue), Reis reluctantly agreed, adding that many infectious diseases were confined to poorer countries ' with a lack of market to develop drugs and vaccines for these neglected diseases.' 'It's very important to create new mechanisms and markets to develop these, not only for Ebola but other tropical diseases. That will prove key', he said. The World Bank was trying to implement a policy of universal health coverage 'with ongoing planning and programmes to raise the general level of health and surveillance systems to enable better preparedness', he added.

\section{Chris Bateman}

chrisb@hmpg.co.za

S Afr Med J 2015;105(6):431-432.

DOI:10.7196/SAMJ.9749 